\title{
Selective Synthesis of Phenanthrenes and Dihydrophenanthrenes via Gold-Catalyzed Cycloisomerization of Biphenyl Embedded Trienynes
}

\author{
Ana Milián, ${ }^{\dagger}$ Patricia García-García, ${ }^{\dagger} *$ Adrián Pérez-Redondo, ${ }^{\dagger}$ Roberto Sanz, ${ }^{\dagger}$ Juan J. Vaquero, ${ }^{\dagger}$ and \\ Manuel A. Fernández-Rodríguez, ${ }^{\dagger} *$ \\ †Departamento de Química Orgánica y Química Inorgánica, Instituto de Investigación Química "Andrés M. del Río" \\ (IQAR). Universidad de Alcalá (IRYCIS). Campus Científico-Tecnológico, Facultad de Farmacia. Autovía A-II, Km 33.1, \\ 28805-Alcalá de Henares, Madrid, Spain. \\ *Área de Química Orgánica, Departamento de Química, Facultad de Ciencias, Universidad de Burgos, Pza. Misael Bañuelos \\ s/n, 09001-Burgos, Spain
}

Supporting Information Placeholder

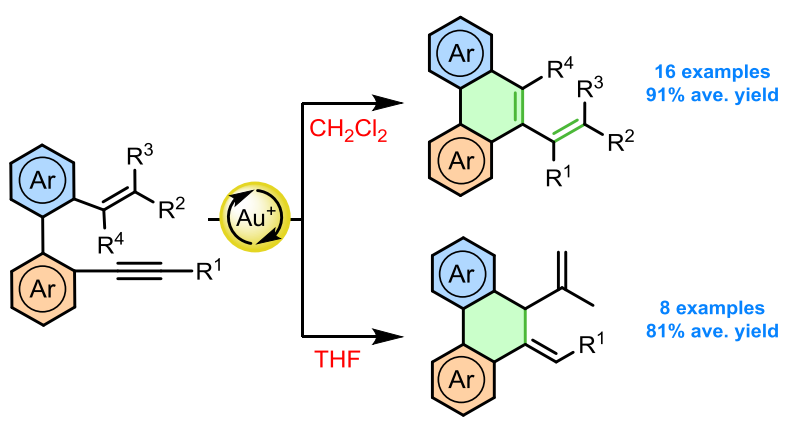

\begin{abstract}
Readily available $o^{\prime}$-alkenyl-o-alkynylbiaryls, a particular type of 1,7-enynes, undergo a selective cycloisomerization reaction in the presence of a gold(I) catalyst to give interesting phenanthrene and dihydrophenanthrene derivatives in high yields. The solvent used provokes a switch in the evolution of the gold intermediate and plays a key role in the reaction outcome.
\end{abstract}

Phenanthrenes and their dihydro derivatives have attracted considerable attention due to their widespread occurrence in natural products and pharmaceuticals with biological activities, which have led to their application in the treatment of microbial or viral infections, allergies, cancer or malaria. ${ }^{1}$ Moreover, phenanthrenes, which are small polycyclic aromatic hydrocarbons (PAHs), ${ }^{2}$ also exhibit outstanding electrochemical and photophysical properties with wide-ranging applications in organic optical and electronic materials. ${ }^{3}$ As a consequence, intensive efforts to construct phenanthrene skeletons with different substitution patterns have been made. The methods described include: oxidative alkenearene or arene-arene couplings in vinyl biaryls and stilbenes ${ }^{4}$ intramolecular McMurry coupling of suitable 2,2'-disubstituted biaryls or related carbonyl or olefin metathesis and carbene dimerizations $;{ }^{5}$ aryne annulations $;{ }^{6}$ metal- or visible light-induced intermolecular cyclizations of ortho-functionalized biaryl derivatives with acetylenes; ${ }^{7}$ metal-catalyzed sequential $\mathrm{Csp}^{2}-\mathrm{Csp}^{2}$ bond-forming reactions; ${ }^{8}$ and electrophilic cycloisomerizations of ortho-alkynylbiaryls. ${ }^{9}$ However, these methods require harsh reaction conditions, densely functionalized starting materials, multistep routes and/or display limited substrate scope and tolerance to functionalities. In addition, procedures to access nonsymmetric and/or selectively substituted phenanthrenes are scarce.
As such, the development of efficient methodologies to synthesize phenanthrenes, or their derivatives, with selective substitution is highly desirable.

Scheme 1. Regioselective synthesis of phenanthrenes by cycloisomerization of $o$-alkynylbiaryls

a) Cycloisomerization of $o$-alkynylbiaryls

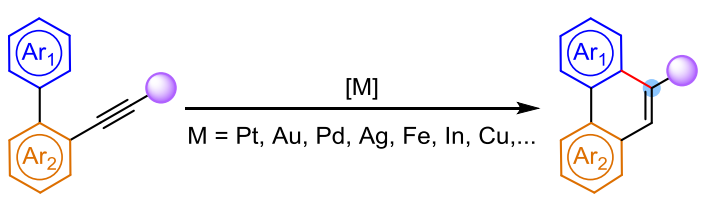

b) This work: cycloisomerization of $o^{\prime}$-alkenyl-o-alkynylbiaryls

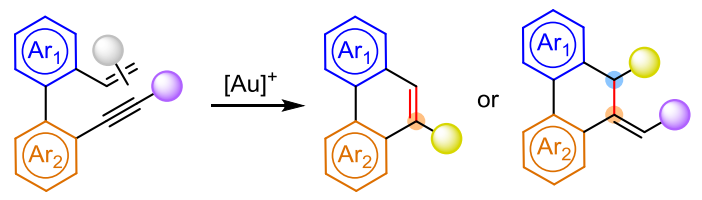


In these regard, metal-catalyzed 6-endo carbocyclizations of biaryls bearing an internal alkyne, which is a general and straightforward route to furnish the phenanthrene core, regioselectively afford phenanthrenes substituted at the carbon next to the arene that acts as a nucleophile $\left(\mathrm{Ar}_{1}\right)$ in the catalytic process (Scheme 1a). ${ }^{9}$ Herein, we describe that, in the presence of cationic gold(I) catalysts, ${ }^{10}$ related $o^{\prime}$-alkenyl-o-alkynylbiaryls, a particular type of 1,7-enynes, ${ }^{11}$ selectively react to produce phenanthrenes substituted at the carbon bonded to the arene $\left(\mathrm{Ar}_{2}\right)$ originally linked to the triple bond (Scheme 1b). Thus, the catalytic method developed provides a complementary synthetic strategy to the most common one depicted in Scheme 1a that differs in the substitution pattern at the internal cycle of the phenanthrene skeleton constructed. Moreover, upon careful selection of the appropriate reaction conditions, mainly the solvent, unsymmetrically $(9,10)$ disubstitued dihydrophenanthrenes can also be prepared from the same starting 1,3,5-trien-7-ynes (Scheme 1b).

Based on our experience in the electrophilic cycloisomerization of ortho-alkynylstyrenes, ${ }^{12}$ we selected 2-(2-methylprop-1-en-1-yl)2'-(phenylethynyl)-1,1'-biphenyl (1a) as model for assessing the reactivity in the presence of gold catalysts. This substrate possesses two nucleophilic entities - an arene and the olefin - in suitable locations to react with the alkyne that would render different cycloadducts. However, we envisioned that the high substitution of the alkene would facilitate its selective 6-exo nucleophilic addition to the metal-activated acetylene, thus furnishing the desired phenanthrene skeleton. At the outset, several gold-derived complexes as catalysts, and different solvents, were studied, and the most significant results are summarized in Table 1 .

Table 1. Optimization of reaction conditions ${ }^{\mathrm{a}}$

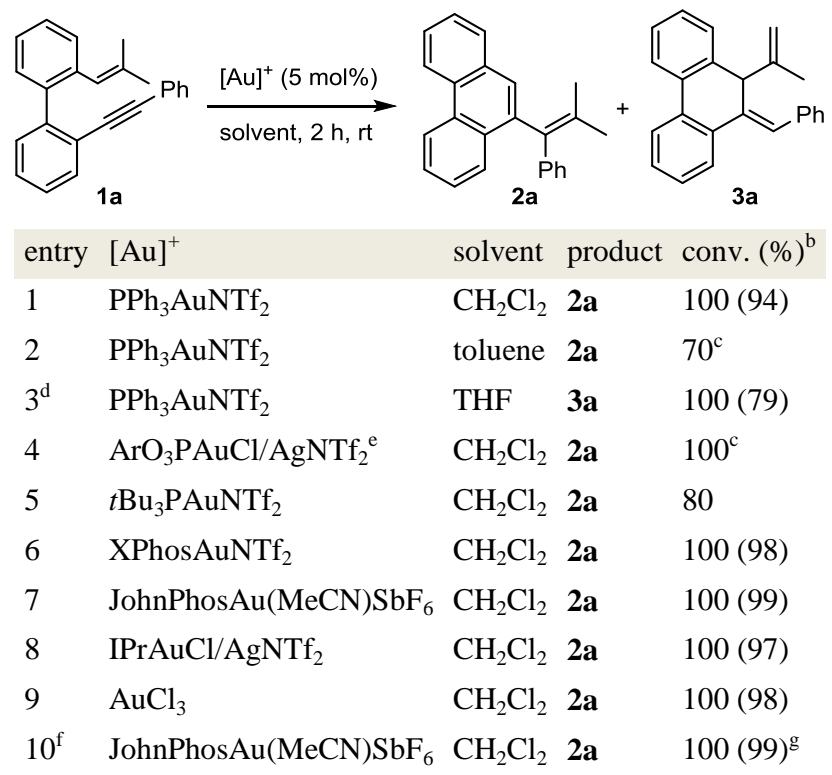

${ }^{\text {a }}$ Reactions conducted using $0.05 \mathrm{mmol}$ of $\mathbf{1 a}$ in $1 \mathrm{~mL}$ of solvent at $25{ }^{\circ} \mathrm{C}$ for $2 \mathrm{~h}$. ${ }^{\mathrm{b}}$ Conversion estimated by ${ }^{1} \mathrm{H}$ NMR spectroscopy $(300 \mathrm{~Hz})$; isolated yield in brackets for an experiment conducted with $0.2 \mathrm{mmol}$ of $\mathbf{1 a}$. $<5 \%$ of $\mathbf{3 a}$ was detected. ${ }^{\mathrm{c}}$ Significant amounts of $\mathbf{3 a}$ and other unidentified products were observed. ${ }^{\mathrm{d}}$ Conducted for $72 \mathrm{~h}$. ${ }^{\mathrm{e}} \mathrm{Ar}=2,4-(t \mathrm{Bu})_{2} \mathrm{C}_{6} \mathrm{H}_{3}{ }^{\mathrm{f}}$ Conducted with $1.0 \mathrm{~mol} \%$ of catalyst. ${ }^{\mathrm{g}}$ Same isolated yield was obtained in an experiment conducted with $1.0 \mathrm{mmol}$ of $\mathbf{1 a}$.

The reaction of $\mathbf{1 a}$ in the presence of $5 \mathrm{~mol} \% \mathrm{AuPPh}_{3} \mathrm{NTf}_{2}$ as catalyst in dichloromethane at room temperature selectively afforded the 9-substituted phenanthrene 2a in less than $2 \mathrm{~h}$ (entry 1). Remarkably, the competitive pathway resulting from addition of the arene to the alkyne, which would produce the corresponding regioisomeric phenanthrene, described in Scheme 1a, was not detected. Encouraged by this initial result, the influence of the solvent on the cycloisomerization of 1a was explored. Thus, the reaction conducted in toluene also gave $\mathbf{2 a}$ as the major product, albeit with lower conversion and selectivity (entry 2). From that crude mixture, the formation of a disubstituted 9,10dihydrophenanthrene 3a was determined. Interestingly, a complete switch in the regioselectivity occurred when THF was employed as solvent and the reaction was conducted for an extended reaction time $(72 \mathrm{~h})$. Thus, under these conditions, dihydrophenanthrene 3a could be selectively obtained in good yield (entry 3). Analogous experiments in THF varying the gold catalyst gave varying mixtures of $\mathbf{2 a}, \mathbf{3 a}$ and other unidentified products, whereas no evolution was observed in other solvents such as acetonitrile or DMF. ${ }^{13}$

The minimal influence of the nature of the cationic gold(I) complex was determined from the outcome of the reactions conducted in DCM. Thus, phenanthrene 2a was obtained exclusively from model substrate 1a in quantitative yields with most of the catalysts tested, including less active gold(III) salts such as $\mathrm{AuCl}_{3}$ (entries 4-9). Of these gold complexes, JohnPhos $\mathrm{Au}(\mathrm{MeCN}) \mathrm{SbF}_{6}$ exhibited a slightly improved selectivity and no traces of the regioisomeric cycloadduct 3a could be detected. Moreover, different temperatures or concentrations resulted in a higher percentage of byproducts, whereas a limited screening with silver salts showed no beneficial effect or improvement in this process. ${ }^{13}$ Finally, lowering the catalyst loading to $1 \mathrm{~mol} \%$ or scaling the reaction to $1 \mathrm{mmol}$ had no impact on either the yield or the reaction time (entry 10). In summary, an appropriate choice of catalyst and solvent allows the selective formation of phenanthrene $\mathbf{2 a}$ (entry 10) and dihydrophenanthrene 3a (entry 3).

With these results in hand, and based on previous studies in the cycloisomerization of $1, n$-enynes, ${ }^{10,11 \mathrm{c}, 12,14}$ we propose the following mechanism that accounts for the formation of both phenanthrene derivatives $\mathbf{2 a}$ and $\mathbf{3 a}$ (Scheme 2).

\section{Scheme 2. Proposed mechanism}

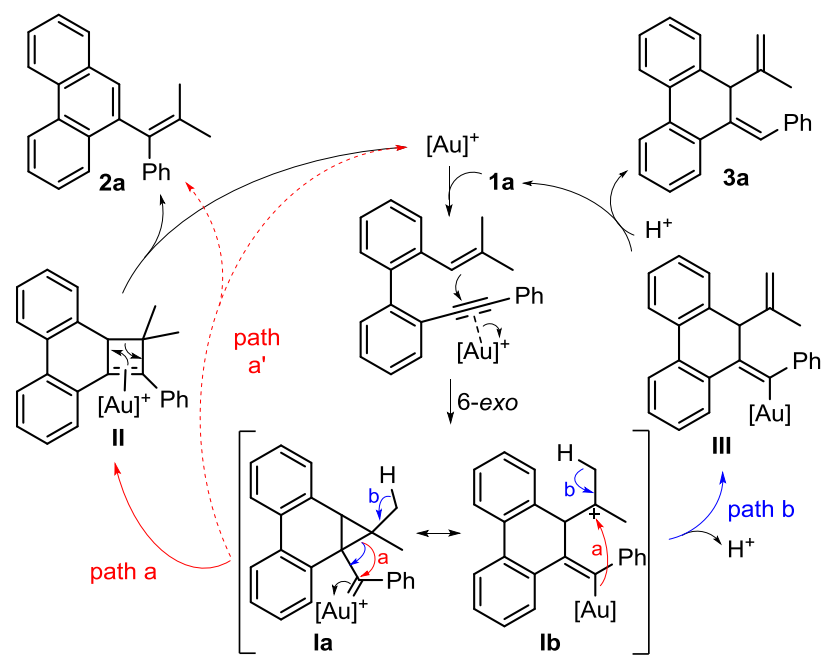

The reaction is initiated upon activation of the acetylene of the starting enyne 1a upon coordination to the gold complex, followed by an intramolecular 6-exo-dig nucleophilic addition of the alkene moiety to give cationic intermediate $\mathbf{I}$. This intermediate can be described as the resonance hybrid of two structures, namely the cyclopropylgold(I) carbene Ia and the gold-stabilized homoallylic carbocation intermediate $\mathbf{I b}$, which delocalizes the positive charge over the molecule. Cyclopropyl ring expansion of 
Ia then furnishes the ( $\eta^{2}$-cyclobutene)gold(I) complex II, ${ }^{15}$ which, after ring opening of the cyclobutene and subsequent demetalation, would lead to phenanthrene $\mathbf{2 a}$ and release the gold catalyst for a new cycle (path a). An alternative pathway (a') involving the direct transformation of intermediate $\mathbf{I}$ into the final phenanthrene, thus avoiding the formation of cyclobutene species II, can also be envisioned. ${ }^{16}$ Both proposed pathways (a/a') are consistent with the well-documented gold-catalyzed, singlecleavage type rearrangements of $1, n$-enynes, which formally imply 1,3-migration of the external carbon of the olefin to the acetylene terminal position of the trienyne $1 \mathbf{a}^{11 \mathrm{c}, 14}$ On the other hand, intermediate I could also undergo a proton elimination, thus giving rise to a vinyl-gold species III (path b). ${ }^{12}$ This pathway is preferred if THF is used as solvent, probably due to the stabilization of the homoallyl cationic resonance structure $\mathbf{I b}$, which favours the elimination event leading to 9,10-dihydrophenathrenes Subsequent protodemetalation would lead to dihydrophenanthrene 3a and regenerate the catalyst.

Having established biphenyl embedded trienyne 1a as a suitable precursor for the intended selective synthesis of phenanthrene $\mathbf{2 a}$, we explored the scope of this catalytic transformation by varying the substitution at the main points of diversity of the molecule (Scheme 3).

\section{Scheme 3. Synthesis of phenanthrene derivatives 2}
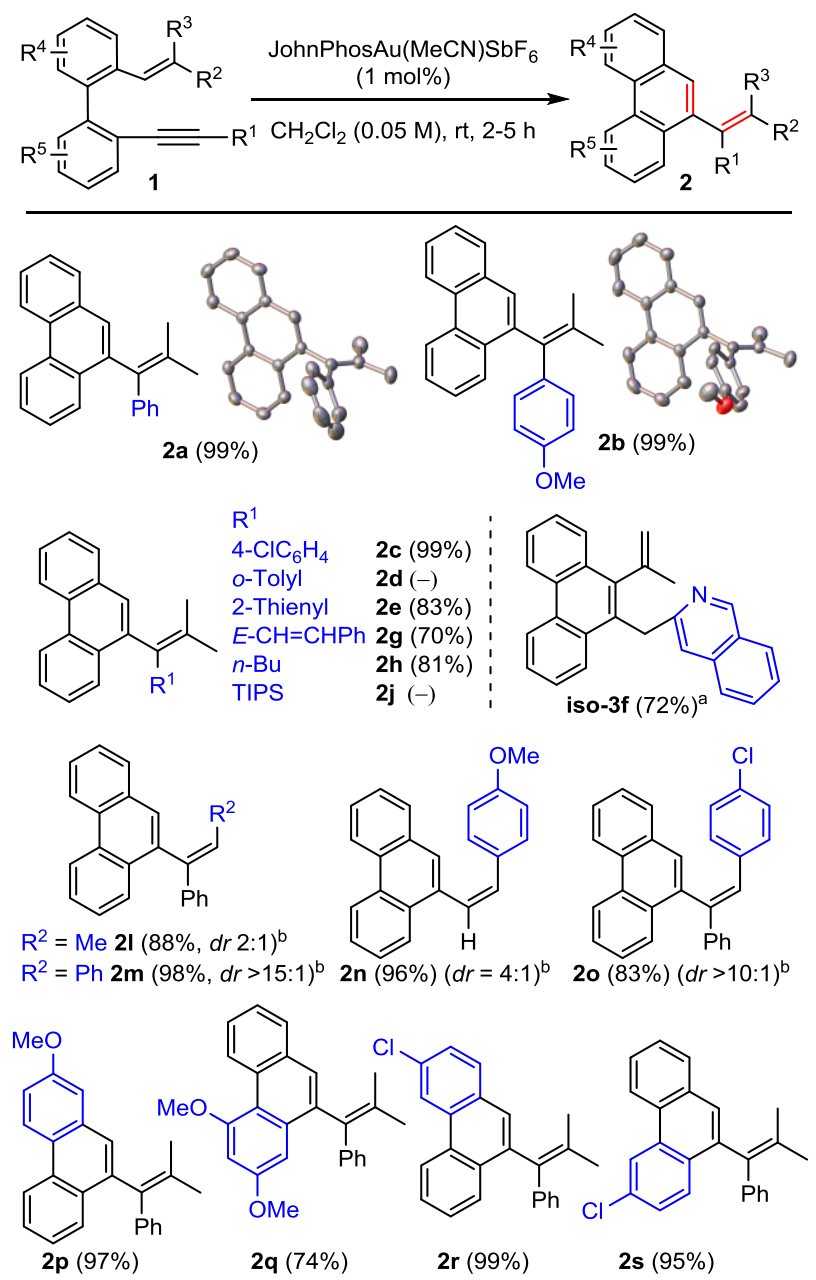

*Isolated yields from reactions performed using $0.4 \mathrm{mmol}$ of 1 . $^{\text {a }}$ Conducted in the presence of PTSA (1 equiv.) for $24 \mathrm{~h} .{ }^{\mathrm{b}}$ Same $d r$ of the starting material, with the exception of $2 \mathbf{n}(\mathbf{1 n} d r>10: 1)$.
As shown, the process developed is tolerant to the presence of a broad range of substituents at the alkyne terminus of the polyunsaturated substrate 1, including aromatic (irrespective of their electronic nature) (1a-c), heteroaromatic (1e), alkenyl (1g), and alkyl groups (1h). However, complex mixtures were observed with 1d bearing an $o$-tolyl substituent, and no evolution was detected with trienyne $\mathbf{1} \mathbf{j}$, which contain a bulkier TIPS group, or quinoline-derived enyne 1f, under the optimized reaction conditions or even after heating at reflux in DCE for $24 \mathrm{~h}$. The outcome for the latter starting material can be rationalized in terms of consumption of the gold catalyst by the nitrogenated heterocycle, thus preventing it from participating in the catalytic cycle. The addition of one equivalent of PTSA to the reaction media avoided this catalytic inhibition, but also triggered the formation of 9,10disubstituted phenanthrene iso-3f instead of the expected 3f. Interestingly, reaction of ethynyl-substituted biphenyl $\mathbf{1 k}$ occurred to give nearly equimolecular mixtures of the corresponding phenanthrene $2 \mathbf{k}$ and dibenzocycloheptatriene $4 \mathbf{k}$ as a result of a formal 7-endo cyclization (Scheme 4). After some experimentation, phenanthrene $\mathbf{2 k}$ could be obtained exclusively in excellent yield using $\mathrm{AuCl}_{3}$ as catalyst, whereas no improvement in the selectivity for $\mathbf{4 k}$ could be achieved. ${ }^{13}$ Reaction of substrate $\mathbf{1 i}$, which bears a trimethylsilyl group, gave a mixture of the same compounds $\mathbf{2 k}$ and $\mathbf{4 k}$ in a similar ratio, thus indicating that desilylation took place prior to the cycloisomerization event.

\section{Scheme 4. Cycloisomerization of terminal substrate $1 \mathrm{k}$}

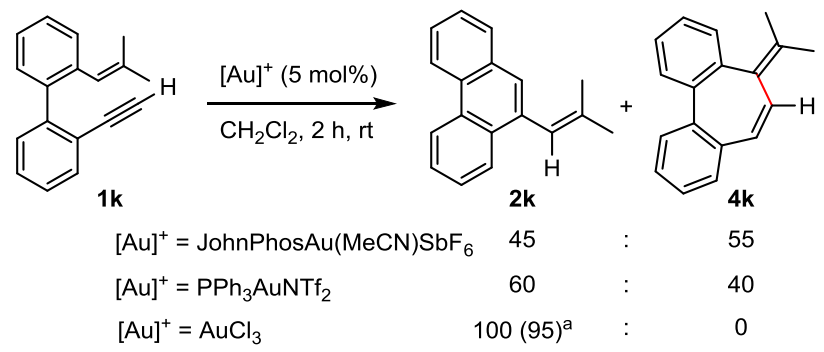

${ }^{\mathrm{a}}$ Isolated yield of reaction performed using $0.4 \mathrm{mmol}$ of $\mathbf{1 k}$.

Next, trienynes 1 with different substitution patterns and electronic properties at the olefin, as well as at the biphenyl core, were evaluated. Thus, we found that reactions of substrates 11-m, alkyl or aryl monosubstituted at the $\beta$ carbon of the styrene moiety, selectively produce the corresponding phenanthrenes $\mathbf{2} \mathbf{l}-\mathbf{m}$ in good to excellent yields with no 7-endo adducts being detected, even with terminal trienyne 1n. Moreover, phenanthrenes 2p-s, which bear electron-donating or -withdrawing substituents at any of the external arenes of the tricyclic skeleton, also proved to be accessible in high yields using the developed methodology starting from appropriately substituted conjugated enynes 1p-s. No competitive addition of the arene that would give phenanthrenes with different substitution patterns (see Scheme 1a), or dihydrophenanthrene $\mathbf{3}$ formation, was observed for any of the substrates tested, with the sole exception of substrate 1f (see above). Furthermore, the structural assignment for phenanthrenes 2, initially determined on the basis of NMR studies, was confirmed by single-crystal X-ray diffraction analysis of $\mathbf{2 a}$ and $\mathbf{2 b}$ (Scheme 3). ${ }^{17}$

We also analyzed the applicability of this catalytic procedure for the construction of unsymmetrically 9,10-disubstituted phenanthrenes, which are not easily accessible using other methods. To this end, less reactive $\alpha$-disubstituted- $\beta, \beta$-unsubstituted styrene substrate 1t was synthesized and submitted to the optimized reaction conditions to afford cyclobutene compound $\mathbf{5 t}$ after $24 \mathrm{~h}$ (Scheme 5). ${ }^{18}$ This tetracyclic compound $\mathbf{5 t}$, the structure of which was confirmed by single-crystal X-ray diffraction 
analysis, ${ }^{17}$ could be transformed into the corresponding desired phenanthrene $2 \mathrm{t}$ simply by heating at $90{ }^{\circ} \mathrm{C}$. Moreover, $2 \mathrm{t}$ could be directly obtained from $1 \mathrm{t}$ by performing the catalytic reaction under the heating conditions. These experiments both expand the scope of the developed methodology to the preparation of unsymmetrically 9,10-disubstituted phenanthrenes and support the participation of cyclobutene species II in the catalytic cycle (see Scheme 2).

Scheme 5. Cycloisomerization of $\alpha$-disubstituted- $\beta$, $\beta$ unsubstituted styrene substrate 1t

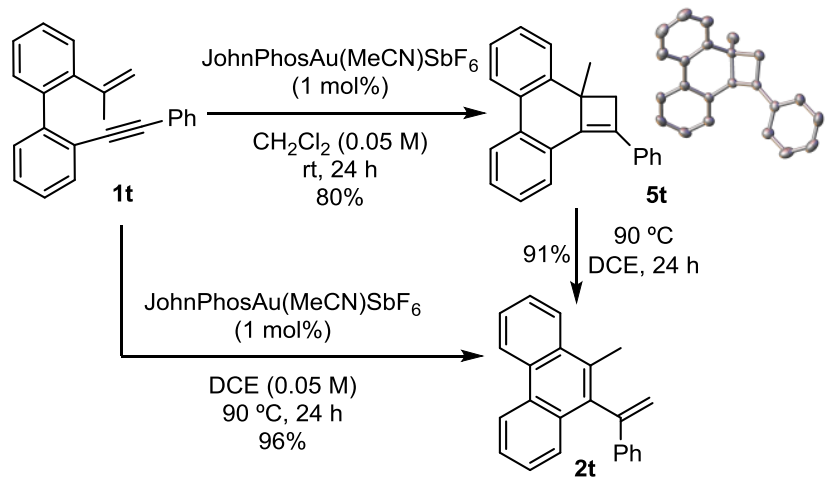

Finally, using the optimized conditions for the preparation of $\mathbf{3 a}$, a family of 9,10-dihydrophenanthrenes 3 that proved the scope and usefulness of this catalytic procedure was synthesized (Scheme 6). Thus, reactions of selected substrates with different substitution at both the alkyne terminus and the biphenyl moiety occurred to form the anticipated disubstituted tricyclic compounds 3 . The yield and selectivity were, in general, very high when using the optimized conditions or heating at $50{ }^{\circ} \mathrm{C}$ for some examples. Only enynes 1b,e, which possess an electron-rich (hetero)arene at the acetylene, led to moderate yields and mixtures with their phenanthrene isomers 2. Moreover, in this case, substrate 1d, which bears an $o$-tolyl group, efficiently evolved to the corresponding dihydrophenanthrene $\mathbf{3 d}$ in good yield. Additionally, the structure of $\mathbf{3 q}$ was confirmed by single-crystal X-ray diffraction analysis (Scheme 6). ${ }^{17}$

\section{Scheme 6. Synthesis of dihydrophenanthrenes 3}
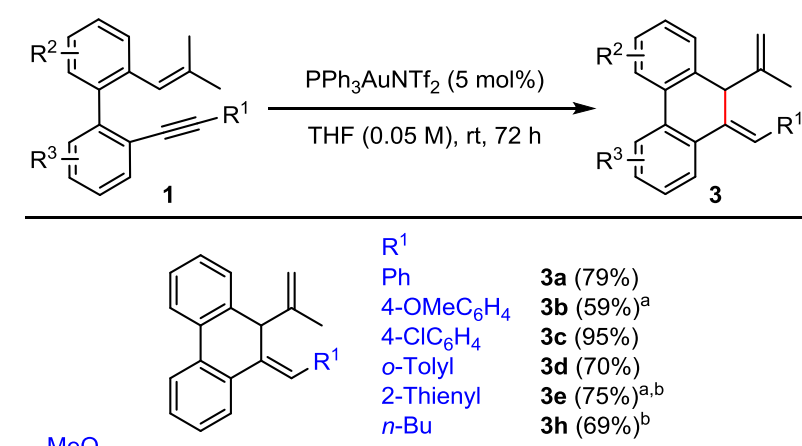<smiles>C=C(C)C1/C(=C\c2ccccc2)c2cc(S(=O)(=O)c3ccccc3)ccc2-c2ccc(OC)cc21</smiles><smiles>C=C(C)C1/C(=C\c2ccccc2)c2cc(OC)cc(OC)c2-c2ccccc21</smiles>

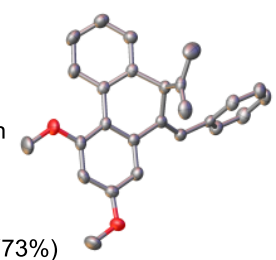<smiles>C=C(C)C1/C(=C\c2ccccc2)c2ccccc2-c2cc(Cl)ccc21</smiles><smiles>C=C(C)C1/C(=C\c2ccccc2)c2ccc(S(=O)(=O)O)cc2-c2ccccc21</smiles>

*Isolated yields of reactions performed using $0.4 \mathrm{mmol}$ of $\mathbf{1}{ }^{\text {a }} \mathrm{A}$ mixture with $2 \mathbf{b}, \mathbf{e}$ was obtained. ${ }^{\mathrm{b}}$ Conducted at $50{ }^{\circ} \mathrm{C}$

In conclusion, we have developed an efficient and solventcontrolled gold-catalyzed synthesis of phenanthrenes and dihydrophenanthrenes from easily available biphenyl embedded trienynes 1. These processes occur with good to excellent yields, broad scope and complete selectivity. Consequently, the phenanthrene synthesis described here is complementary to the well-developed strategy that produces regioisomeric phenanthrenes resulting from the competitive nucleophilic addition of biphenyl to the activated alkyne. Further studies on the reactivity of biphenyl embedded trienynes that provide straightforward access to other relevant policyclic scaffolds via new and selective reaction pathways are currently underway in our laboratories and will be reported in due course.

\section{ASSOCIATED CONTENT}

\section{Supporting Information}

The Supporting Information is available free of charge on the ACS Publications website.

Experimental details, NMR spectra for all new compounds and $\mathrm{X}$ ray crystallographic data for $\mathbf{2 a}, \mathbf{b} ; \mathbf{3 q}$ and $\mathbf{5 t}(\mathrm{PDF})$.

\section{AUTHOR INFORMATION}

\section{Corresponding Authors}

*E-mail: patricia.garciagarci@uah.es

*E-mail: mangel.fernandezr@uah.es

\section{Author Contributions}

The manuscript was written with contributions from all authors

\section{ACKNOWLEDGMENT}

We are grateful to the Ministerio de Economía y Competitividad (MINECO), AEI and FEDER (projects CTQ2017-85263-R and CTQ2016-75023-C2-1-P), Instituto de Salud Carlos III (FEDER funds, ISCIII RETIC REDINREN RD16/0009/0015), Junta de Castilla y León and FEDER (BU291P18), and University of 
Alcalá (projects CCGP2017-EXP/016 and CCG2018/EXP-008 and predoctoral contract for A. M.) for financial support.

\section{REFERENCES}

(1) (a) Han, J.; Xian, Z.; Zhang, Y.; Liu, J.; Liang, A. Systematic overview of aristolochic acids: nephrotoxicity, carcinogenicity, and underlying mechanisms. Front. Pharmacol. 2019, 10, 648-665. (b) Li, X.; Qiao, Y.; Wang, X.; Ma, R.; Li, T.; Zhang, Y.; Borris, R. P. Dihydrophenanthrenes from Juncus ef fusus as inhibitors of OAT1 and OAT3. J. Nat. Prod. 2019, 82, 832-839. (c) Jing, Y.; Zhang, Y.F.; Shang, M.-Y.; Yu, J.; Tang, J.-W.; Liu, G.-X.; Li, Y.-L.; Li, X.M.: Wang, X.; Cai, S.-Q. Phenanthrene derivatives from roots and rhizomes of Asarum heterotropoidesvar. mandshuricum Fitoterapia 2017, 117, 101-108. (d) Kanekar, Y.; Basha, K.; Duche, S.; Gupte, R.; Kapat, A. Regioselective synthesis of phenanthrenes and evaluation of their anti-oxidant based anti-inflammatory potential. Eur. J. Med. Chem. 2013, 67, 454-463. (e) Ikeda, T.; Yaegashi, T.; Matsuzaki, T.; Hashimoto, S.; Sawada, S. Asymmetric synthesis of phenanthroindolizidine alkaloids with hydroxyl group at the C14 position and evaluation of their antitumor activities. Bioorg. Med. Chem. Lett. 2011, 21, 342-345. (f) Yang, X.; Shi, Q.; Bastow, K. F.; Lee, K.-H. Antitumor agents 274. A new synthetic strategy for E-ring SAR study of antofine and cryptopleurine analogues. Org. Lett. 2010 12, 1416-1419. (g) Wang, X.-Y.; Ke, C.-Q.; Tang, C.-P.; Yuan, D.; Ye, Y. 9,10-Dihydrophenanthrenes and phenanthrenes from Juncus setchuensis. J. Nat. Prod. 2009, 72, 1209-1212. (h) Bouchaud, O.; Imbert, P.; Touze, J. E.; Dodoo, A. N.; Danis, M.; Legros, F. Fatal cardiotoxicity related to halofantrine: a review based on a worldwide safety data base. Malar. J. 2009, 8, 289-297. (i) Lin, J.-C.; Yang, S.C.; Hong, T.-M.; Yu, S.-L.; Shi, Q.; Wei, L.; Chen, H.-Y.; Yang, P.C.; Lee, K.-H. Phenanthrene-based Tylophorine-1 (PBT-1) inhibits lung cancer cell growth through the Akt and NF- $\mathrm{KB}$ pathways. $J$. Med. Chem. 2009, 52, 1903-1911. (j) Kovács, A.; Vasas, A.; Hohmann, J. Natural phenanthrenes and their biological activity. Phytochemistry 2008, 69, 1084-1110.

(2) (a) Segawa, Y. Ito, H.; Itami, K. Structurally uniform and atomically precise carbon nanostructures. Nat. Rev. Mater. 2016, 1, 15002. (b) Narita, A.; Wang, X.-Y.; Feng, X.; Müllen, K. New advances in nanographene chemistry. Chem. Soc. Rev. 2015, 44, 6616-6643. (c) Wang, C.; Dong, H.; Hu, W.; Liu, Y.; Zhu, D. Semiconducting $\pi$ conjugated systems in field-effect transistors: A material odyssey of organic electronics. Chem. Rev. 2012, 112, 2208-2267.

(3) (a) Li, M.; An, C.; Marszalek, T.; Guo, X.; Long, Y.-Z.; Yin, H.; Gu, C.; Baumgarten, M.; Pisula, W.; Müllen, K. Phenanthrene condensed thiadiazoloquinoxaline donor-acceptor polymer for phototransistor applications. Chem. Mater. 2015, 27, 2218-2223. (b) Wang, S.; Yan, X.; Cheng, Z. Zhang, H.; Liu, Y.: Wang, Y. Highly efficient near-infrared delayed fluorescence organic light emitting diodes using a phenanthrene-based charge-transfer compound. Angew. Chem., Int. Ed. 2015, 54, 13068-13072. (c) He, Z.; Xu, X.: Zheng, X.; Ming, T.; Miao, Q. Conjugated macrocycles of phenanthrene: a new segment of [6,6]-carbon nanotube and solution-processed organic semiconductors. Chem. Sci. 2013, 4, 4525-4531.

(4) (a) Zhao, Z.; Britt, L. H.; Murphy, G. K. Oxidative, Iodoarenecatalyzed intramolecular alkene arylation for the synthesis of polycyclic aromatic hydrocarbons. Chem. Eur. J. 2018, 24, 17002-17005. (b) Niphakis, M. J.; Georg, G. I. Synthesis of Tylocrebrine and related phenanthroindolizidines by $\mathrm{VOF}_{3}$-mediated oxidative aryl-alkene coupling. Org. Lett. 2011, 13, 196-199. (c) Wang, K.; Lü, M.; Yu, A.; Zhu, X.; Wang, Q. Iron(III) chloride catalyzed oxidative coupling of aromatic nuclei. J. Org. Chem. 2009, 74, 935-938. (d) Almeida, J. F.; Castedo, L.; Fernández, D.; Neo, A. G.; Romero, V.; Tojo, G. Base-induced photocyclization of 1,2-diaryl-1-tosylethenes. A mechanistically novel approach to phenanthrenes and phenanthrenoids. Org. Lett. 2003, 5, 4939-4941

(5) (a) McAtee, C. C.; Riehl, P. S.; Schindler, C. S. Polycyclic aromatic hydrocarbons via iron(III)-catalyzed carbonyl-olefin metathesis. J. Am. Chem. Soc. 2017, 139, 2960-2963. (b) Xia, Y.; Liu, Z.; Xiao, Q.; Qu, P.; Ge, R.; Zhang, Y.; Wang, J. Rhodium(II)- catalyzed cyclization of bis( $N$ - tosylhydrazone)s: an efficient approach towards polycyclic aromatic compounds. Angew. Chem., Int. Ed. 2012, 51, 5714-5717. (c) Katz, T. J.; Sivavec, T. M. Metal-catalyzed rearrangement of alkene-alkynes and the stereochemistry of metallacyclobutene ring opening. J. Am. Chem. Soc. 1985, 107, 737-738. (d) McMurry, J. E. Carbonyl-coupling reactions using lowvalent titanium. Chem. Rev. 1989, 89, 1513-1524.

(6) (a) Liu, Z.; Larock, R. C. Palladium-catalyzed, sequential, three-component cross-coupling of aryl halides, alkynes, and arynes. Angew. Chem., Int. Ed. 2007, 46, 2535-2538. (b) Peña, D.; Pérez, D.; Guitián, E.; Castedo, L. Palladium-catalyzed cocyclization of arynes with alkynes: selective synthesis of phenanthrenes and naphthalenes. J. Am. Chem. Soc. 1999, 121, 5827-5828.

(7) (a) Yan, J.; Yoshikai, N. Phenanthrene synthesis via chromiumcatalyzed annulation of 2-biaryl Grignard reagents and alkynes. Org. Lett. 2017, 19, 6630-6633. (b) Xiao, T.; Dong, X.; Tang, Y.; Zhou, L. Phenanthrene synthesis by Eosin Y-catalyzed, visible light-induced [4+2] benzannulation of biaryldiazonium salts with alkynes. Adv. Synth. Catal. 2012, 354, 3195-3199. (c) Matsumoto, A.; Ilies, L.; Nakamura, E. Phenanthrene synthesis by iron-catalyzed [4+2] benzannulation. between alkyne and biaryl or 2-alkenylphenyl Grignard reagent. J. Am. Chem. Soc. 2011, 133, 6557-6559. (d) Wang, C.; Rakshit, S.; Glorius, F. Palladium-catalyzed intermolecular decarboxylative coupling of 2-phenylbenzoic acids with alkynes via $\mathrm{C}-\mathrm{H}$ and $\mathrm{C}-\mathrm{C}$ bond activation. J. Am. Chem. Soc. 2010, 132, 1400614008. (e) Shi, Z.; Ding, S.; Cui, Y.; Jiao, N. A palladium- catalyzed oxidative cycloaromatization of biaryls with alkynes using molecular oxygen as the oxidant. Angew. Chem. Int. Ed. 2009, 48, 7895-7898.

(8) (a) Zhao, Q.; Fu, W. C.; Kwong, F. Y. Palladium- catalyzed regioselective aromatic extension of internal alkynes through a norbornene- controlled reaction sequence. Angew. Chem., Int. Ed. 2018, 57, 3381-3385. (b) Fu, W. C.; Wang, Z.; Chan, W. T. K.; Lin, Z.; Kwong, F. Y. Regioselective synthesis of polycyclic and heptagon- embedded aromatic compounds through a versatile $\pi$ - extension of aryl halides. Angew. Chem., Int. Ed. 2017, 56, 7166-7170. (c) Iwasaki, M.; Araki, Y.; Nishihara, Y. Phenanthrene synthesis by palladium-catalyzed benzannulation with $o^{-}$bromobenzyl alcohols through multiple carbon-carbon bond formations. J. Org. Chem. 2017, 82, 6242-6258. (d) Ozaki, K.; Murai, K.; Matsuoka, W.; Kawasumi, K.; Ito, H.; Itami, K. One- step annulative $\pi$ - extension of alkynes with dibenzosiloles or dibenzogermoles by palladium/o- chloranil catalysis. Angew. Chem., Int. Ed. 2017, 56, 1361-1364. (e) Shoji, Y.; Tanaka, N.; Muranaka, S.; Shigeno, N.; Sugiyama, H.; Takenouchi, K.; Hajjaj, F. Fukushima, T. Boronmediated sequential alkyne insertion and $\mathrm{C}-\mathrm{C}$ coupling reactions affording extended $\pi$-conjugated molecules. Nat. Commun. 2016, 7 , 12704-12710. (f) Shimizu, M.; Nagao, I.; Tomioka, Y.; Hiyama, T. Palladium- catalyzed annulation of vic- bis(pinacolatoboryl)alkenes and phenanthrenes with 2,2'- dibromobiaryls: facile synthesis of functionalized phenanthrenes and dibenzo $[g, p]$ chrysenes. Angew. Chem., Int. Ed. 2008, 47, 8096-8099.

(9) For selected recent references see: (a) Hartung, T.; Machleid, R.; Simon, M.; Golz, C.; Alcarazo, M. Enantioselective synthesis of 1,12-disubstituted [4]helicenes. Angew. Chem. Int. Ed. 2020, 59, 5660-5664. (b) Nicholls, L. D. M.; Marx, M.; Hartung, T.; GonzálezFernández, E.; Golz, C.; Alcarazo, M. TADDOL-derived cationic phosphonites: toward an effective enantioselective synthesis of [6]helicenes via Au-catalyzed alkyne hydroarylation. ACS Catal. 2018, 8, 6079-6085. (c) Zeng, Z.; Jin, H.; Sekine, K.; Rudolph, M.; Rominger, F.; Hashmi, A. S. K. Gold-catalyed regiospecific C-H annulation of $o$-ethynylbiaryls with anthranils: $\pi$-extension by ringexpansion en route to N-doped PAHs. Angew. Chem., Int. Ed. 2018, 57, 6935-6939. (d) Saunthwal, R. K.; Danodia, A. K.; Saini, K. M.; Verma, A. K. Ag(I)-catalyzed cycloisomerization reactions: synthesis of substitutedphenanthrenes and naphthothiophenes. Org. Biomol. Chem. 2017, 15, 6934-6942. (e) González-Fernández, E.; Nicholls, L. D. M.; Schaaf, L. D.; Farès, C.; Lehmann, C. W.; Alcarazo, M. Enantioselective synthesis of [6]carbohelicenes. J. Am. Chem. Soc. 2017, 139, 1428-1431. (f) Jin, R.; Chen, Y.; Liu, W.; Xu, D.; Li, Y. Ding, A.; Guo, H. Merging photoredox catalysis with Lewis acid catalysis: activation of carbon-carbon triple bonds. Chem. Commun. 2016, 52，9909-9912. (g) Aguilar, E.; Sanz, R.; Fernández- 
Rodríguez, M. A.; García-García, P. 1,3-Dien-5-ynes: versatile building blocks for the synthesis of carbo- and heterocycles. Chem. Rev. 2016, 116, 8256-8311 and references cited therein. For seminal work by Fürstner's group, see: (h) Mamane, V.; Hannen, P.; Fürstner, A. Synthesis of phenanthrenes and polycyclic heteroarenes by transition- metal catalyzed cycloisomerization reactions. Chem. Eur. J. 2004, 10, 4556-4575. (i) Fürstner, A.; Mamane, V. Concise total synthesis of the Aporphine Alkaloid 7,7'-bisdehydro-Omethylisopiline by an $\mathrm{InCl} 3$ mediated cycloisomerization reaction. Chem. Commun. 2003, 2112-2113. (j) Fürstner A.; Mamane, V. Flexible synthesis of phenanthrenes by a $\mathrm{PtCl}_{2}$-catalyzed cycloisomerization reaction. J. Org. Chem. 2002, 67, 6264-6267.

(10) For selected reviews on Au-catalyzed cycloisomerization reations of enynes, see: (a) Echavarren, A. M.; Muratore, M. N.; López-Carrillo, V.; Escribano-Cuesta, A.; Huguet, A.; Obradors, C. Gold-catalyzed cyclizations of alkynes with alkenes and arenes. Org. React. 2017, Vol. 92: Chap 1. (b) Dorel, R.; Echavarren, A. M. Gold(I)-catalyzed activation of alkynes for the construction of molecular complexity. Chem. Rev. 2015, 115, 9028-9072. (c) Obradors, C.; Echavarren, A. M. Gold-catalyzed rearrangements and beyond. Acc. Chem. Res. 2014, 47, 902-912. (d) Jiménez-Núñez, E.; Echavarren, A. M. Gold-catalyzed cycloisomerizations of enynes: a mechanistic perspective. Chem. Rev. 2008, 108, 3326-3350. (e) Michelet, V.; Toullec, P. Y.; Genet, J. P. Cycloisomerization of 1,n- enynes: challenging metal- catalyzed rearrangements and mechanistic insights. Angew. Chem., Int. Ed. 2008, 47, 4268-4315.

(11) For selected references on cycloisomerization of 1,7-enynes see: (a) Dorel, R.; McGonigal, P. R.; Echavarren, A. M. Hydroacenes made easy by gold(I) catalysis. Angew. Chem., Int. Ed. 2016, 55, 11120-11123. (b) Meiß, R.; Kumar, K.; Waldmann, H. Divergent Gold(I)-Catalyzed Skeletal Rearrangements of 1,7-Enynes. Chem. Eur. J. 2015, 21, 13526-13530. (c) Cabello, N.; Rodríguez, C.; Echavarren, A. M. Gold-catalyzed cyclizations of 1,7-enynes. Synlett 2007, 1753-1758.

(12) (a) Virumbrales, C.; Solas, M.; Suárez-Pantiga, S.; FernándezRodríguez, M. A.; Marín-Luna, M.; Silva López, C.; Sanz, R. Gold(I)-catalyzed nucleophilic cyclization of $\beta$-monosubstituted $o$ (alkynyl)styrenes: a combined experimental and computational study. Org. Biomol. Chem. 2019, 17, 9924-9932. (b) Virumbrales, C.; Suárez-Pantiga, S.; Solas, M.; Fernández-Rodríguez, M. A.; Sanz, R. Gold(I)-catalyzed diastereoselective synthesis of 1- $\alpha$-oxybenzyl- $1 H$ indenes. Org. Biomol. Chem. 2018, 16, 2623-2628. (c) GarcíaGarcía, P.; Sanjuán, A. M.; Rashid, M. A.; Martínez-Cuezva, A.; Fernández-Rodríguez, M. A.; Rodríguez, F.; Sanz, R. Synthesis of functionalized $1 \mathrm{H}$-indenes and benzofulvenes through iodocyclization of $o$-(alkynyl)styrenes. J. Org. Chem. 2017, 82, 1155-1165. (d) Sanjuán, A. M.; Virumbrales, C.; García-García, P.; FernándezRodríguez, M. A.; Sanz, R. Formal [4+1] cycloadditions of $\beta, \beta$ diaryl-substituted ortho-(alkynyl)styrenes through gold(I)-catalyzed cycloisomerization reactions. Org. Lett. 2016, 18, 1072-1075. (e) Sanjuán, A. M.; Rashid, M. A.; García-García, P.; Martínez-Cuezva, A.; Fernández-Rodríguez, M. A.; Rodríguez, F.; Sanz, R. Gold(I)catalyzed cycloisomerizations and alkoxycyclizations of ortho(alkynyl)styrenes. Chem. Eur. J. 2015, 21, 3042-3052. (f) GarcíaGarcía, P.; Rashid, M. A.; Sanjuán, A. M.; Fernández- Rodríguez, M. A.; Sanz, R. Straightforward synthesis of dihydrobenzo[a]fluorenes through $\mathrm{Au}(\mathrm{I})$-catalyzed formal [3+3] cycloadditions. Org. Lett. 2012,
14, 4778-4781. (g) Sanz, R.; Martínez, A.; García-García, P.; Fernández-Rodríguez, M. A.; Rashid, M. A.; Rodríguez, F. Halocyclization of $o$-(alkynyl)styrenes. Synthesis of 3-halo- $1 \mathrm{H}$ indenes. Chem. Commun. 2010, 46, 7427-7429. (h) Martínez, A.; García-García, P.; Fernández-Rodríguez, M. A.; Rodríguez, F.; Sanz, R. Gold(I)-catalyzed enantioselective synthesis of functionalized indenes. Angew. Chem., Int. Ed. 2010, 49, 4633-4637.

(13) See Supporting Information for further details.

(14) (a) García-Morales, C.; Echavarren, A. M. From straightforward gold(I)-catalyzed enyne cyclizations to more demanding intermolecular reactions of alkynes with alkenes. Synlett 2018, 29, 22252237. (b) Dorel, R.; Echavarren, A. M. Gold-catalyzed reactions via cyclopropyl gold carbene-like intermediates. J. Org. Chem. 2015, 80, 7321-7332. (c) Obradors, C.; Echavarren, A. M. Intriguing mechanistic labyrinths in gold(I) catalysis. Chem. Commun. 2014, 50, 16-28. (d) Escribano-Cuesta, A.; Pérez-Galán, P.; Herrero-Gómez, E.; Sekine, M.; Braga, A. A. C.; Maseras, F.; Echavarren, A. M. The role of cyclobutenes in gold(I)-catalysed skeletal rearrangement of 1,6enynes. Org. Biomol. Chem. 2012, 10, 6105-6111. (e) Hashmi, A. S. $\mathrm{K}$. Homogeneous gold catalysis beyond assumptions and proposals-characterized intermediates. Angew. Chem., Int. Ed. 2010, 49, 5232-5241. (f) Nieto-Oberhuber, C.; López, S.; Muñoz, M. P.; Cárdenas, D. J.; Buñuel, E.; Nevado, C.; Echavarren, A. M. Divergent mechanism for the skeletal rearrangement and $[2+2]$ cycloaddition of enynes catalyzed by gold. Angew. Chem., Int. Ed. 2005, 44, 6146-6148.

(15) Direct formation of cyclobutenyl intermediates II from goldactivated substrates $\mathbf{1}$ cannot be discarded, see reference: Brooner, R. E. M; Brown, T. J.; Widenhoefer, R. A. Direct observation of a cationic gold(I)-bicyclo[3.2.0]hept-1(7)-ene complex generated in the cycloisomerization of a 7-phenyl-1,6-enyne. Angew. Chem. Int. Ed. 2013, 52, 6259-6261.

(16) The formation of single-cleavage adducts from 1,6-enynes generally proceeds via direct cyclopropyl ring opening ( $a^{\prime}$-like pathway, see ref. 10,14) due to the low stability of strained bicyclo[3.2.0]hept-5-enes that should be formed in the stepwise mechanism analogous to path a. However, for 1,7-enynes, the higher stability of the corresponding bicyclo[4.2.0]oct-6-ene intermediates allowed the reaction to proceed via either of these pathways (ref 14d).

(17) CCDC-2011662 (2a), 2011663 (2b), 2011664 (3q), and 2011665 (5t) contain the supplementary crystallographic data for this paper. These data can be obtained free of charge from The Cambridge Crystallographic Data Centre via www.ccdc.cam.ac.uk/data request/cif.

(18) For selected references on metal-catalyzed cyclobutene formation from enynes see: (a) Obradors, C.; Leboeuf, D.; Aydin, J.; Echavarren; A. M. Gold(I)-catalyzed macrocyclization of 1,n-enynes. Org. Lett. 2013, 15, 15761579. (b) Odabachian, Y.; Gagosz, F. Cyclobutenes as isolable intermediates in the gold(I)-catalysed cycloisomerisation of 1,8-enynes. Adv. Synth. Catal. 2009, 351, 379386. (c) Fürstner, A.; Schlecker, A.; Lehmann, C. W. Facile formation of iodocyclobutenes by a ruthenium-catalyzed enynecycloisomerization. Chem. Commun. 2007, 42774279. (d) Fürstner, A.; Davies, P. W.; Gress, T. Cyclobutenes by platinumcatalyzed cycloisomerization reactions of enynes. J. Am. Chem. Soc. 2005, 127, 82448245. See also references $14 d$,f. 